\title{
A.JO'「E
}

African Journal of Teacher Education

ISSN 1916-7822. A Journal of Spread Corporation

Volume 10. No. 12021 Pages 222-241

\section{Factors in Teachers' Awareness of Pedagogical Gestures as Enhancement Technique Among English Teachers in Secondary Schools in Enugu State, Nigeria}

\author{
Nkechinyere Iwe \\ Michael Okpara University of Agriculture, Umudike, Nigeria
}

\begin{abstract}
The study seeks to ascertain Nigerian language teachers' awareness of pedagogical gestures as an enhancement to teaching and whether this awareness is influenced by teaching location and teacher qualification. The study adopts the survey research design with a sample size of 262 drawn using multi-staged sampling techniques. The Z-test method was used in testing the hypothesis of the study. It was discovered that there was high mean response of teachers on the awareness of pedagogical gestures. There were significant differences in the mean response of urban/rural teachers and no significant differences in the mean response of graduate/non-graduate teacher's awareness of pedagogical gestures as enhancement technique. Our conclusion is that pedagogical gestures are indispensable in lesson delivery and that their pedagogic values are gained through awareness of them as enhancement technique.
\end{abstract}

Key words: Gestures, teachers, pedagogical gestures, language classroom, awareness

\section{Background}

Gesturing complements the segmented and combinational forms that characterize speech and, by so doing, it serves as an enhancement to speech. Communication usually consists of a blend of verbal and non-verbal transmission of information and the two strongly complement each other. For instance, when telling a story, there is invariably body movement of different types. These body movements translate into gesture which allows the speaker to convey a number of messages. Gestures are therefore movements of the parts of the body (eye, hand, head, fingers, leg) that complement speech in human communication and their study fall into an aspect of linguistics 
referred to as paralinguistics or semiotics. Kelly, Manning, and Rodak, (2008) suggest that teachers can use gesture to become even more effective in several fundamental aspects of their profession, including communication, assessment of their students' knowledge and ability so as to instill a profound understanding of abstract concepts in traditionally difficult domains such as language and mathematics. They further maintain that even a casual observation of teachers and students interacting in the classroom will reveal that gestures are as pervasive and indispensable as black boards, desks and lesson plans.

The general claim, therefore, is that adding gesture to spoken instruction makes the instruction more effective. It promotes learning when it is used in teaching contexts. In other words, children are more likely to benefit more from instruction when it is accompanied by gestures than when it is not. This means that the gestures that teachers produce during instructions, termed teaching gestures/pedagogical gestures could facilitate learning by helping children understand the concepts that accompany those gestures. This is because information is presented to them in two rather than one modality - speech and gesture.

Teachers use teaching gestures/pedagogical gestures to capture the attention of the students and make their lessons more dynamic and more understandable. According to Tellier (2008), such gestures appear in various shapes: hand gestures, facial expressions, pantomime, body movements and so on. These gestures help learners to infer the meaning of spoken words or expressions.

Even in second language learning like Gulberg's (2008) study has shown, teachers use of gesture help to assist learners especially, struggling ones to grapple with aspects of the new language. Gulberg studied the role of gesture in second language learning and strongly recommended the use of visually rich gestures such as iconic gestures. This is to strengthen his claim that such gestures serve as ideal input to beginning learners of a second language. According to Gulberg, the best source of gestural information is the language teacher who is able to observe behavior in the two cultures (that of the native speakers and that of the second language learners) and use appropriate gestures to teach the language in his own classroom. (Gulberg, 2008). Such teachers are considered to be a lot more effective than those who do not take all the pains. The question is, "how aware are teachers of their use of these gestures as enhancement techniques in the classroom? It is against this background that the present study is designed to investigate Nigerian teachers' awareness of pedagogical gestures as enhancement techniques in the English 
language classroom. The study is planned to examine the influence of such variables as teachers' education, and location.

\section{Gestures in language classroom}

Communication is multimodal, consisting of a blend of verbal and non-verbal transmission of information. Gestures are part of the non-verbal modalities of communication. Scholarly appreciation of gestures dates back to the work of $18^{\text {th }}$ century philosophers, Abbe de Condillac (cited in Hewe, 1973) who propounded gestural theory which claims that language evolved from manual gestures. Godwin (1986) suggests that gestures are "highly organized activities that contain temporal, spatial and social properties"' (p.47). Gesture, from Godwin's perspective, is a time and space related — not a continuous - activity. It accompanies speech or sometimes is used alone for the purpose of communication. However, that gestures are highly organized is debatable. When a speaker unconsciously uses gestures to accompany speech especially in informal communication or when children use gestures to call the attention of their caregivers before they acquire language, their gesturing is not organized. If gestures are employed in informal spontaneous use, then we are not inclined to believe that they are organized activities. Gestures do not follow a particular pattern or system as spoken language. Gesturing as a mode of communication lacks rules that guide its usage and process, so Godwin's definition, from our view, does not pass our review.

McNeil (1992) sees gesture as "an integral part of language as much as are words, phrases, and sentences - gesture and language are one system'”(p.2). This implies that language complements gesture and speech. There are no separate gesture languages from speech language. McNeill further claims that there are two elements of the speech-gesture relationship that are particularly interesting: Firstly, co-speech gestures do not make sense without the accompanying speech. Secondly and related to the first, is that gesture and speech combine to reveal meaning that goes beyond the sum of the two individual parts. For instance, according to McNeill (1992), a friend simply telling you how he got involved in an auto crash will not make clear the picture of the incident without gesturing how the cars collided. The addition of this iconic gesture would surely provide a much clearer and more elaborate representation of what happened (p.3). Based on McNeil's definition, communication without the use of gestures both in formal and informal setting is incomplete. This is supported by Bates and Dick (2002) who in their study of gesture 
and development posit that since gesture and speech form an integrated system, gesture should play an important role in language and cognitive development.

Studies have shown the effect of gesture on second language memorization by young children. Tellier (2008) as well as Goldin - Meadow and Alibali (2013) show that gestures promote deeper learning and retention of knowledge much better than does lessons without gestures. Teachers' gestures, therefore, can be said to have a substantial impact on students' learning, as a teacher's inclination to support difficult material with gesture may be precisely what their students need to grasp a challenging material.

Given that teachers' gestures affect the information that students take up from a lesson, and given that teachers can alter their gestures if they wish to do so, Goldin - Meadow and Alibali (2013) think that it may be worthwhile for teachers to use gestures in a planned and purposeful fashion to reinforce the message they intend to convey. Furthermore, in the light of evidence that the use of gesture can itself promote learning, teachers may also wish to encourage children to produce gestures themselves, as such encouragement may serve to activate their implicit knowledge, making them particularly receptive to instruction (Broaders, Cook, Mitchell \& Goldin - Meadow, 2007).

Similarly, Cook and Goldin-Meadow (2006) suggest that gesturing can free-up mental capacity and can also influence the process of information exchange between teachers and students. They observe a potential advantage of gesturing in assessment, suggesting that teachers could be trained to incorporate gesture in making more appropriate student appraisals. Biau and Soto-Faraco (n.d, p.69) also record modulated auditory integration at two stages of learning; the early stage, and a later time when beat gestures synchronize with speech. Beat gestures produced along with speech have been found to modulate brain activity in listeners (Hubbard, Wilson, Callan \& Dapretto, 2009). These works show that gestures constitute a very prominent part of the paralinguistic context in which listeners perceive spoken messages.

\section{Statement of the problem}

Studies have shown that gestures are indispensable complement to everyday speech. Each gesture has a shape and conveys meaning used to reinforce speech. Of particular interest to this study is the finding that gestures perform pedagogical function by serving as enhancement tool for the 
teacher in lesson delivery. English language teachers in $\mathrm{L}_{1}$ countries, it is believed, are consciously aware of pedagogical gestures, their nature, and pedagogical functions, and purposely use them in their lesson delivery as enhancement tools. However, the extent to which Nigerian teachers of English in secondary schools share this awareness is unclear. Since research findings in gesture studies have revealed that pedagogical gestures are facilitators of learning in the English language classroom, it is, therefore, important to investigate teachers' awareness of pedagogical gesture and their forms and their semantic import in the classroom in order to bring to the fore the importance of pedagogical gestures in lesson delivery.

\section{Aim and research questions}

The study aims to determine Nigerian English language teachers' awareness of pedagogical gestures as enhancement technique in the English Language classroom, and whether location and qualification -induced teacher stereotypes influence teachers' awareness of pedagogical gestures. The specific research questions were:

(1) To what extent does urban teachers' awareness of pedagogical gestures differ from those of their rural counterparts?

(2) To what extent does graduate teachers' awareness of pedagogical gesture differ from those of their counterparts without graduate qualifications?

The following hypotheses were formulated:

Ho1 There is no significant difference between the mean responses of urban teachers on awareness of pedagogical gestures from those of their rural counterparts.

$\mathrm{Ho}_{2}$ There is no significant difference between the mean responses of graduate teachers on awareness of pedagogical gestures from those of their non-graduate counterparts.

\section{Briefs on literature review}

Gestures in teaching has attracted varied research attention such as Roth (2001), Valenzeno, Alibali and Klatzky (2003), Church, Ayman-Nolley and Mahootian (2004), Lazaraton (2004), Pozzer-Ardebghi and Roth (2007), Nikazm (2008), Tara and Megan (2009), Macedonia and Knosche (2011), Macedonia and Kriegstein (2012), Oluikpe (2014). Gesture studies have contributed significantly to our understanding of child language acquisition. It has also contributed 
immensely to adult communication. Experimental studies have shown that pedagogical gestures facilitate the teaching of English (Macedonia and Knosche 2011), Macedonia and Kriegstein (2012 and are effective enhancement tools in the English language classroom. In the light of research findings in pedagogical gestures, this responds to Neill and Caswell (1995) and Olsher's (2008) call for teachers to be aware of the gestures they use in the language classroom. Consequently, this study sensitizes Nigerian English teachers to gestures they either consciously or unconsciously use in the language classroom as enhancement techniques.

\section{Theoretical framework}

This researcher adopted the Lexical Gesture Process Model (LGPM) as propounded by Krauss, Chen, and Gottesmann (2001) which holds that the primary function of iconic gestures, which they call lexical gestures, is to facilitate lexical access in speech production. In the words of the proponents:

Lexical gestures occur only as accompaniments to speech, but vary considerably in length, are non-repetitive, complex and changing in form and many appear to bear a meaningful relation to the semantic content of the speech they accompany. They are somewhat similar to ideational gestures such as hand-arm movements that consist of more than two independent vectorial components (p.90).

Describing the model, Mol and Kita (2013) observe that the primary function of lexical gestures is not to convey imagistic information to an interlocutor, but rather to facilitate the speaker-internal process of word retrieval. In their words,

LGPM model is designed to explain the claim that lexical gestures facilitate word form retrieval. The basic idea is that the motor program for the gesture of a certain Visio-spatial representation, created from a number of its spatial features, functions as a cross-modal prime for word form retrieval. The model assumes that lexical gestures are similar to iconic gestures. The higher rate of iconic gestures per word may be caused by attempts to facilitate the word retrieval that is difficult for speakers with non-fluent aphasia. Assuming that some speakers have more difficulty retrieving words, they will then generate more gestures to counteract this difficulty (p.201). 
The lexical gesture process model relates to speech production as it assumes that lexical gestures and speech involve three production stages that operate in concert: conceptualizing, formulating, and articulating (Krauss, Chen, and Gottesmann, 2001).

Conceptualizing involves, among other things, drawing upon declarative and procedural knowledge to construct a communicative intention. The output of the conceptualizing stage- $\mathrm{a}$ preverbal message - is a conceptual structure containing a set of semantic specifications. At the formulating stage, the preverbal message is transformed in two ways. First, a grammatical encoder maps the to-be-lexicalized concept onto a lemma (i.e., an abstract symbol representing the selected word as a semantic-syntactic entity) in the mental lexicon whose meaning matches the content of the preverbal message. Using syntactic information contained in the lemma, the conceptual structure is transformed into a surface structure (see also Bierwisch \& Schrueder, 1992). Then, by accessing word forms stored in lexical memory and constructing an appropriate plan for the utterance's prosody, a phonological encoder transforms this surface structure into a phonetic plan (essentially a set of instructions to the articulatory system). The output of the articulatory stage is overt speech, which the speaker monitors and uses as a source of corrective feedback. Alibali (2000) summarizes the model thus: "At what point in the process of speech production is gesture involved? Gesture is involved in generating the surface forms of utterances. Specifically, gesture facilitates access to items in the mental system" (p.89).

The model is found relevant to this study in that it accounts for gestures as facilitative of speech by ensuring that words or lexical items stored in the brain are retrieved in the process of conversation or speech initiation. And to this extent, it equally captures the social dimension of gestures as enhancement strategy in speech-based venture or communicative activity.

\section{Methodology}

The study adopted the survey research design which entails selecting a sample from a population which is representative enough to make valid generalizations. Baran (1999, p.350) supports this as he observes thus: "Survey allows researchers to measure characteristics, opinions or behavior of a population by studying a small sample from that group generalizing back to the population, which is the group under scrutiny" The singular advantage of extensiveness in size and spread makes the choice of survey appropriate for the study. 
The area of study is Enugu State in south-east Nigeria. Enugu state has seventeen Local Government Areas. The population of this study is 1,746 which is the population of English teachers in the 291 public secondary schools in Enugu State of Nigeria (Enugu State Secondary Education Board, 2017).

On the Sample Size and Sampling Technique, the 'Population-Percentage recommendation' method has been adopted in determining the sample size of this study. In line with this method, some scholars have recommended sample sizes for specific population sizes. We have adopted the recommendations of Berg and Gall (1973) which are as follows:

Above 5000 population $=$ above 20 percent as sample, below $5000=$ around $10-15$ percent..." Equally, a sample size between 10 percent and 25 percent is recommended as acceptable when determining sample size of studies with population of few thousands. In all, some factors like cost, project type, and time should be considered.

In line with the above recommendations, since the population is1,746 the sample size of the study is $15 \%$ of the population of the study."

$$
\frac{1746}{100} \times \frac{15}{1}=261.9 \text { Approx. } 262
$$

A mixed and multi-staged sampling technique was adopted in selecting the sample namely: Balloting sampling, proportionate sampling and accidental sampling techniques. The balloting sampling yields three educational zones in Enugu state namely: Enugu, Agbani, and Nsukka educational zones. The balloting involved writing the names of all the six educational zones in Enugu state on paper, putting them in a bowl; shaking them properly at every pick without replacement until three educational zones were picked.

The second stage involved proportionate sampling where the sample (262) was proportionately distributed among the three educational zones based on urban versus rural location with urban having higher percentage than rural schools because of population being higher in urban former schools. The last stage is where the accidental/missionary/available sampling method was used to select English teachers from schools in the zones as shown in Table 1 below: 


\begin{tabular}{|l|l|l|l|}
\hline S/N & Zone and Location & Proportion sample & $\begin{array}{l}\text { Proportion } \\
\text { percentage }\end{array}$ \\
\hline 1 & Agbani, Urban & 54 & $21 \%$ \\
\hline 2 & Agbani, Rural & 33 & $12 \%$ \\
\hline 3 & Enugu, Urban & 50 & $19 \%$ \\
\hline 4 & Enugu, Rural & 37 & $14 \%$ \\
\hline 5 & Nsukka, Urban & 59 & $23 \%$ \\
\hline 6 & Nsukka, Rural & 29 & $11 \%$ \\
\hline & Total & $\mathbf{2 6 2}$ & $\mathbf{1 0 0 \%}$ \\
\hline
\end{tabular}

Table 1: Breakdown of Sampling Method

Data for the study were collected using a self-constructed 4-point Likert-type questionnaire. The questionnaire was patterned into two (2) sections; section A to elicit the respondents' biodata and sections $\mathrm{B}$ to $\mathrm{D}$ to generate data on different types of gestures especially pedagogical gestures and teachers' awareness of them. Section B contains 20 related questions that border on teachers' awareness of typical everyday gestures. Section C contains 20 questions on teachers' awareness of pedagogical gestures.

To ensure reliability of the instrument, a pilot study was conducted using some teachers of other subjects in Umuahia, Abia State. The instrument was administered to the subjects on two separate occasions with a gap of two months. This approach in establishing reliability is called Test-retest method or measure of stability.

Nwahunanya \& Akanwa (2008 p.63) observe that in this method, "The same test is given to the same group of testees on more than one occasion. Then the scores obtained by the group on the first administration are correlated with the scores obtained from the same group of testees on the second administration of the same test. The reliability coefficient in this case will simply be the correlation between the two sets of scores by the same testees on two administrations of the same test" Thus, the Spearman's rank correlation coefficient was used for the test, which formula is given as:

$\mathrm{r}_{\mathrm{s}} \quad=1-6 \Sigma_{\mathrm{d} 2} / \mathrm{n}\left(\mathrm{n}^{2}-1\right)$

AJOTE Vol. 10.1 (2021), 222-243 


$\begin{array}{rll}\mathrm{r}_{\mathrm{S}} & = & \text { Spearman's rank correlation coefficient } \\ \Sigma_{\mathrm{d} 2} & = & \text { Sum of squared }{ }^{\mathrm{d}} \mathrm{d} . \\ \mathrm{n} & = & \text { Number of subjects (paired ranks) }\end{array}$

A correlation figure of 0.81 was gotten which was considered high enough for the administration of the questionnaire to the actual sample.

Validity refers to the extent to which an instruction is capable of doing what it is expected to do (Nwahunanya \& Akanwa, 2008). The study adopted the Face validity option. It pertains to whether the test looks valid to the examinees who take it, the administrative personnel who decide on its use, and the technically untrained other observers (Anastasi \& Urbiria, 1997). In adopting this method, three research scholars were consulted to assess the relative inclusiveness, adequacy as well as the grammatical coverage of the items in the measuring instruments. The amendments by the expert gave the instruments some validity.

Two hundred and sixty-two (262) copies of questionnaire were distributed to respondents on different days for the urban and rural secondary schools. The researcher also observed the teachers who were selected for the study during their lessons for one month and made use of research assistants in the course of the observation and administration of questionnaire. There was close monitoring of the respondents and the research assistants in the course of administration of the questionnaire to ensure a reduction or avoidance of mortality or invalid filling of the copies of the questionnaires. A brief orientation was also organized for the respondents on the intents of the research to ensure that possible biases and prejudices were taken care of or avoided. Sixty-two copies of questionnaire were invalid hence 200 copies were returned valid and used for the study. Below is a breakdown of the percentage of returned and valid copies of the questionnaire:

\begin{tabular}{|l|l|l|}
\hline Returned & 200 & $76 \%$ \\
\hline Invalid & 62 & $24 \%$ \\
\hline Total & 262 & $100 \%$ \\
\hline
\end{tabular}

\section{Table 2: Breakdown of Questionnaire Distribution}

Data for the study were presented and analyzed using the Likert scale of 4 points to determine the significance of each of the instrument items. Each of the items was analyzed using the Likert scale and decision value of 3.00 was adopted in determining the significance. In this AJOTE Vol. 10.1 (2021), 222-243 
method, strongly agree (SA) is allotted 4, Agree is allotted 3, strongly disagree is allotted 2, and disagree is 1 . Also, the means and grand means were calculated for each of the categories of the questions.

The Z-Test method was adopted in testing the hypotheses of this study. The method is considered apt because the hypotheses were to determine the significance between two means (A two-tailed test). Also, we considered the Z — test method because as alluded by Kothari (1997), Ztest is suitable for studies with high sample from 30-above. The Z-test method formula is:

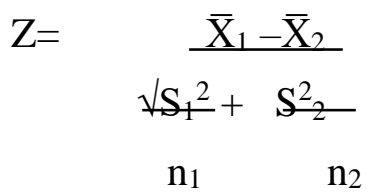

Where: $\bar{X}=$ the mean/grand mean as the case may be

$\mathrm{S}=$ Standard deviation

$\mathrm{n}=$ sample

\section{Decision rule:}

1) Reject the null hypothesis if the calculated $Z(Z c a l)$ is greater than the (Zcrit) critical value.

2) Accept if, the $Z$ critical value is less than the $Z$ calculated value.

\section{Data Presentation, Analysis, and Discussion}

Data analysis and presentation is based on the returned/valid $200(76 \%)$ copies of questionnaire. 
Table 3: Difference between Urban and Rural Teachers' Mean Response on Awareness of Pedagogical Gestures

$\begin{array}{ll}\text { Urban } & \text { Rural } \\ \left(X_{1}\right)=101 & \left(X_{2}\right)= \\ & 99\end{array}$

\section{Statement}

1 Pedagogical gestures are those used by teachers as enhancement technique to help the student learn.

2 They involve either the movement of a part or 3143.10 combination of parts of the body.

3 They are classified based on their pedagogical function. 304

4 Iconic gesture is a pedagogical gesture generally used to 291 depict visually an action or an object.

5 Iconic gesture involves stretching a close fist through the 326 window to demonstrate a throw.

6 It also involves demonstrating the need to warm up the 316 body in cold weather by rubbing the palms together.

7 Iconic gesture includes holding tight the first to 341 demonstrate insistence.

8 It may be expressed by making a loud clap to 356 demonstrate an auto crash

9 Iconic gesture also involves punching the fists in the air 361 to demonstrate a fight.

10 It may be in the form of making some bodily action like 308 walking fast to demonstrate a quick action.

11 Deictic gesture is a pedagogical gesture generally used $299 \quad 2.96$ to refer to abstract/concrete pointing.

12 It may be in the form of pointing to an object in the 341 immediate environment.

13 It could be used to represent past action by pointing 361 behind one.

14 It could also be in the form of flicking the finger up and 301 down to describe a particular object.
$3.00 \quad 392$

3.95

2.88

398

4.02

3.22

401

4.05

3.12

389

3.92

386

3.52

391

388

3.04

371

3.74

359

3.62

3.37

382

3.85

3.57

374

3.77

2.98

368

3.71 
15 It may involve flicking the finger back and forth to

bacon on someone or draw students' attention in class.

16 Metaphoric gesture is a pedagogical gesture, which concepts

17 Metaphoric gesture involves gesturing with the hand in an upward movement to indicate high intelligence.

18 It could also be in the form of a spherical pantomime to 308 represent the idea of wholeness.

19 Metaphorical gesture may involve opening the two palms before students to demonstrate emptiness or nothingness.

$\begin{array}{llll}301 & 2.98 & 384 & 3.87\end{array}$

20 It may be in the form of a sluggish movement to demonstrate dullness or slow learning.

Total

Grand mean $\left(\mathrm{X}_{1}\right)=\sum \overline{\mathrm{X}} / \mathbf{n}=\mathbf{6 0 . 6 4 / 2 0}=\mathbf{3 . 0 3}$

\section{$6136 \quad 60.64 \quad 7638 \quad 77.01$}

From the values of the grand mean, it is evident that the mean response of both urban and rural teachers on awareness of pedagogical gestures is above the 3.00 decision point. A slight differential however exists as the rural teachers mean response is above that of their urban counterparts. The significance of the differential shall be established when the hypothesis is tested.

It is necessary to observe that from the analysis above, rural teachers' awareness of pedagogical gestures seemingly vary from that of their urban counterparts. This is important considering the observation of Comley (2013) that demographic features of students as well as method of teaching are some factors that could trigger some variation in knowledge and perhaps implementation of pedagogical gestures in lesson activities. Teachers in Nigeria's rural settings often deal with students who are comparatively of low social status and with relatively low exposure to contemporary learning aids. This situation seems able to trigger a higher level of awareness and use of pedagogical gestures as enhancement technique among rural teachers. 
Table 4: Difference Between Graduate and Non-graduate Teachers' Mean Response on Awareness of Pedagogical Gestures

Graduate
$\left(\mathbf{X}_{1}\right)=$

157

\section{Statement}

1 Pedagogical gestures are those used by 529 teachers as enhancement technique to help the student learn.

2 They involve either the movement of a part or 531 combination of parts of the body.

3 They are classified based on their pedagogical 496 function.

4 Iconic gesture is a pedagogical gesture 494 generally used to depict visually an action or an object.

5 Iconic gesture involves stretching a close fist 501 through the window to demonstrate a throw.

6 It also involves demonstrating the need to 521 warm up the body in cold weather by rubbing the palms together.

7 Iconic gesture includes holding tight the first to 518 demonstrate insistence.

8 It may be expressed by making a loud clap to 534 demonstrate an auto crash

9 Iconic gesture also involves punching the fists 498 in the air to demonstrate a fight.

10 It may be in the form of making some bodily 541 action like walking fast to demonstrate a quick action.

11 Deictic gesture is a pedagogical gesture 486 generally used to refer to abstract/concrete pointing.
Non-

graduate

$\left(\mathbf{X}_{2}\right)=\mathbf{4 3}$

$\overline{\mathbf{X}} \quad \sum \mathbf{F} \overline{\mathbf{X}}$

$\overline{\mathbf{X}}$

3.36

69

1.60

3.38

71

1.65

$3.15 \quad 65$

3.14

57

3.19

68

1.58

3.31

75

1.74

3.29

76

1.76

3.40

81

1.88

$3.17 \quad 65$

1.51

3.44

70

1.62

3.09

59

1.37 
12 It may be in the form of pointing to an object 501

in the immediate environment.

13 It could be used to represent past action by 519

72

pointing behind one.

14 It could also be in the form of flicking the 520

$3.31 \quad 58$

1.34

finger up and down to describe a particular object.

15 It may involve flicking the finger back and 528

$3.36 \quad 64$

1.48

forth to bacon on someone or draw students'

attention in class.

16 Metaphoric gesture is a pedagogical gesture, 517

$3.29 \quad 72$

1.67

which uses concrete demonstration to describe abstract ideas or concepts

17 Metaphoric gesture involves gesturing with 495

$3.15 \quad 82$

1.90

the hand in an upward movement to indicate high

intelligence.

18 It could also be in the form of a spherical 521

$3.31 \quad 64$

1.48

pantomime to represent the idea of wholeness.

19 Metaphorical gesture may involve opening 532

69

1.60

the two palms before students to demonstrate emptiness or nothingness.

20 It may be in the form of a sluggish movement 530

$3.37 \quad 74$

1.72

to demonstrate dullness or slow learning.

\section{Total}

Grand mean $\left(\mathrm{X}_{1}\right)=\sum \overline{\mathrm{X}} / \mathbf{n}=62.27 / 20=3.11$ $\begin{array}{lll}10312 & 62.27 & 1373\end{array}$

36.33

Grand mean $\left(\mathrm{X}_{1}\right)=\sum \overline{\mathrm{X}} / \mathbf{n}=\mathbf{3 6 . 3 3} / \mathbf{2 0}=\mathbf{1 . 8 1}$

The values above show that while the grand mean for the graduate teachers is above the decision value of 3.00, that of the non-graduate teachers is less than the decision value. This is interpreted as a differential in the mean response of graduate and Non-graduate teachers on awareness of pedagogical gestures. The mean response of graduate teachers is higher than that of their nongraduate counterparts. It is striking that being a university graduate presupposes some level of exposure and training in teacher effectiveness as well as in how to communicate in the classroom for easy learner's comprehension. Teaching practice affords graduate teacher trainees an 
opportunity to develop their skills as well as be abreast of modern strategies and techniques for effective teaching (National Teachers Conference Report, 2010); a form of training that is not available to their non-graduate counterparts.

\section{Hypotheses Testing}

Hypothesis One-(HO $\left.\mathbf{H}_{1}\right)$ - There is no significant difference between the mean response of Urban teachers on awareness of pedagogical gestures from those of their Rural counterparts

Table 5: Z-Test of the Significant Difference Between the Mean response of Urban and Rural Teachers on Awareness of Pedagogical Gestures

\begin{tabular}{|l|l|l|l|l|l|}
\hline Variables & $\begin{array}{l}\text { Mean }(\text { Grand } \\
\text { mean } \overline{\mathbf{X}})\end{array}$ & $\begin{array}{l}\text { Standard } \\
\text { Deviation }(\mathbf{S D})\end{array}$ & $\begin{array}{l}\text { Z-calculated } \\
\left(\mathbf{z}_{\text {cal }}\right)\end{array}$ & $\begin{array}{l}\text { Z-Critical } \\
\left(\mathbf{z}_{\text {crit }}\right)\end{array}$ & Decision \\
\hline Urban $\left(\overline{\mathrm{X}}_{1}\right)$ & 3.03 & $11.023\left(\mathrm{~S}_{1}\right)$ & -1.19 & 1.96 & Rejection \\
\hline Rural $\left(\overline{\mathrm{X}}_{2}\right)$ & 3.85 & $12.421\left(\mathrm{~S}_{2}\right)$ & & & \\
\hline
\end{tabular}

\section{$-1.19>1.96=$ Rejection}

Applying the decision rule, the Tcal is greater than the Tcrit hence the null hypothesis is rejected; thus, there is significant difference between the mean responses of urban teachers on the awareness of pedagogical gestures from their rural counterparts.

Urban and rural dichotomy is based on location and has been found to influence training and capacity building which are necessary for (improved) awareness of pedagogical gestures as enhancement technique in lesson delivery. The report of the National Teachers Conference (2012) captured and addressed this lack of equity. It noted that since all teachers have the same mission there should not be discrimination in terms of location, age, or gender and that equal opportunities should be provided for all for optimum job performance. However, Mahdi and Al-Dera (2013, p71) observe that the location of teachers reflects differences in the use and adoption of ICT. Thus while "Teachers sampled showed no differential in their level of awareness and knowledge of ICTs, there are differences in terms of urban and rural teachers' use or adoption of new technologies for teaching" (emphasis is ours).

Hypothesis two $\left(\mathbf{H O}_{2}\right)$ - There is no significant difference between the mean response of graduate teachers on awareness of pedagogical gestures from those of their non-graduate counterparts. 
Table 6: Z-Test of the Significant Difference Between the Mean Response of Graduate and Non-graduate Teachers on Awareness of Pedagogical Gestures

\begin{tabular}{|l|l|l|l|l|l|}
\hline Variables & $\begin{array}{l}\text { Mean } \\
(\text { Grand mean } \\
\overline{\mathbf{X}})\end{array}$ & $\begin{array}{l}\text { Standard } \\
\text { Deviation }(\text { SD })\end{array}$ & $\begin{array}{l}\text { Z- } \\
\text { calculated } \\
\left(\mathbf{z}_{\text {cal }}\right)\end{array}$ & $\begin{array}{l}\text { Z-Critical } \\
\left(\mathbf{z}_{\text {crit }}\right)\end{array}$ & Decision \\
\hline Graduate $\left(\overline{\mathrm{X}}_{1}\right)$ & 3.11 & $11.46\left(\mathrm{~S}_{1}\right)$ & 1.80 & 1.96 & Acceptance \\
\hline $\begin{array}{l}\text { Non-graduate } \\
\left(\overline{\mathrm{X}}_{2}\right)\end{array}$ & 1.81 & $7.978\left(\mathrm{~S}_{2}\right)$ & & & \\
\hline
\end{tabular}

\section{$1.80<1.96=$ Acceptance}

From the table above, the Tcalculated is less than the Tcritical hence the null hypothesis is accepted thus: there is no significant difference between the mean responses of graduate teachers from those of their non-graduate counterparts. It could be interpreted that the variable of graduate/non-graduate does not induce a significant difference in the awareness of pedagogical gestures among the respondents. Graduate and non-graduate certification seem to not be an issue in teacher awareness of pedagogical gestures because both graduate and non-graduate teachers are exposed to some training that could enable them have knowledge on and be aware of pedagogical gestures as enhancement techniques in lesson delivery.

\section{Summary and Conclusion}

We have shown that gestures are used among Nigerian language teachers in Enugu state, and that awareness of pedagogical gestures is high among these teachers. It has been revealed that location and qualification-induced difference influence teacher' awareness of pedagogical gestures as enhancement technique. Some differentials were obtained in the mean responses of teachers across the variables of urban/ rural, and graduate/ non-graduate. The differentials were that rural (R) were more than urban $(\mathrm{U})(\mathrm{R}=3.85, \mathrm{U}=3.03)$, and graduate $(\mathrm{G})$ more than non-graduate teachers $(\mathrm{NG})(\mathrm{G}=3.11, \mathrm{NG}=1.81)$.

However, when subjected to statistical z-test, the results indicated that the differentials were not significant for qualification hence there were no significant differences in the mean response of graduate and non-graduate teachers' awareness of pedagogical gestures as enhancement technique. But the differential between urban and rural were found to be significant hence there is significant difference in the mean response of urban and rural teacher's awareness of pedagogical gestures as enhancement technique in lesson delivery. In the case of qualification 
that showed no significant differential, the Zcal (1.80 for qualification) is less than the Zcrit (1.96) at 0.05 significance level while for location that showed significant differential, the Zcal (-1.19) is greater than the Zcrit (-1.96) at 0.05 significance level. It was on the bases of the hypothesis test results that we inferred that while qualification -induced teacher stereotype do not influence teacher's awareness of pedagogical gestures, location-induced teacher stereotypes influence teacher's awareness of pedagogical gestures as enhancement technique. Our conclusion is that pedagogical gestures are indispensable in lesson delivery and that their pedagogic values are gained through awareness of them as enhancement technique.

\section{References}

Ajadu, K. (2013). Appraisal of workers performance and skills acquisition in south western Nigeria. International journal of Labour matters, 2, pp7-15.

Alibali, M.W. (2000). Effects of visibility between speaker and listener on gesture Production: Some gestures are meant to be seen. Journal of Memory and Language, 44, Pp.89-124. Anastali, et'al (1997). Language development in children. Language issues, 2, pp80-121.

Baran, S. J. (1999). Introduction to mass communication, media literacy and culture. USA:

\section{McGraw Hill.}

Bates, L and Dick U. (2002). Gestures and speech development. Cognitive sciences, 2, pp90-123

Berg, K. and Gall, J. (1973). Research methodologies. New York: Apprentice.

Bierwisch, G. \& Shrueder, K. (1992). An evaluation of early development in children with autism and pervasive developmental disorders from home movies: Preliminary findings. Autism; 2, Pp. 243-58.

Cooks, K. and Goldin-Meadow,S. (2006). Gestures, speech production and message retention. Gestures, 2.

Condillac, K. (2005). Taxonomies of gestures. In R. Gells (Ed). Cognitive studies. New Delhi: Prentice.

Comley, K. (2013). Development studies in gestures. Development studies Quarterly, 2, pp78-81 
Goldin-Meadow, S. and Alibali, K. (2013). Co-speech gestures in language learning. Cognitive sciences 2, pp6-21.

Gulberg, M. (2008). Gestures and second language acquisition. In C. Nick \& P. Robinson (Eds). Handbook of Cognitive Linguistics and Second Language Acquisition. New Delhi: Prentice. Pp.276-305.

Heeks, R.B. (2002). Research design and approach. California: Prentice.

Hubbard, D., Wilson, M., Callan, J., and Dapretto, O. (2009). Beat gestures and brain activities. Language cognition, 3, pp5-17.

Kelly, S., Manning, S. \& Rodak, S. (2008). Gesture gives a hand to Language and Learning: Perspectives from cognitive neuroscience development psychology and education. sLanguage and Linguistic Compass 2, (10) 1-16.

Krauss, R. M, Chen Y, Gottenmann, L. (2001). Nonverbal behavior and nonverbal communication: What do conversational hand gestures tell us? Advances in Experimental Social Psychology.19, 389-450.

Lazaraton, A. (2004). Gesture and speech in the vocabulary explanations of one ESL teacher: A macroanalytic enquiry. Language Learning, 54 (1), 79-117.

Macedonia, M. \& Knosche, T. (2011). Body in mind: how gestures empower foreign language learning. Mind, Brain, and Education 5, 196-211.

McNeil, D. (1992) Triangulating the growth point -arriving at consciousness. In L. Messing \& R, Campbell (Eds), Gesture, speech and sign (77-92). New York, NY: Oxford University Press.

Mol, D. \& Kita, S. (2013). What does cross-linguistic variation in semantic coordination of speech and gesture reveal? Evidence for an interface representation of spatial thinking and speaking. Journal of Memory and Language.48, 16-32.

AJOTE Vol. 10.1 (2021), 222-243 
Nikasm, C. (2008). Gestures in foreign language classrooms: An empirical analysis of their organization and function. In M. Bowles et al. (Eds), Second language research reform. Somerville, MA: Cascadilla Proceedings Project.

Nwahunnaya, C. \& Akanwa, U. (2008). A Practical guide to research and project Writing.

Owerri: Springfield.

Nwanna, O.C. (1981). Educational statistics and research. Enugu: Layman.

Oluikpe, E. (2014). The Pattern and function of vocalization and gesture in Nigerian mother-infant interaction. Greener Journal of Education Research, 4 (2), Pp.041-051.

Pozzer-Ardenghi, L. \& Roth, W. (2007). On performing concepts in Science Lectures. Science Education, 91 (1), 96-114.

Roth, W. (2001). Gestures: Their role in teaching and learning. Review of Educational Research, $71(3), 365-392$.

Tara, M. (2009). How do teachers' gestures help young children in second language acquisition? Proceedings of the meeting of International Society of Gesture Studies, ISGS 2005: Interaction Bodies, June 15th-18th ENS Lyon, France. Retrieved fromhttp://gesturelyon2005.ens- ish.fr/IMG/pdf/TellierFINAL.pdf.

Tellier, M. (2008). The effect of gestures on second language memorization by young children. Retrieved on $17^{\text {th }}$ June 2016 from https://hal.archives-ouvertes.fr/hal-00375251.

Valenzeno, L., Alibali, W. \& Klantzky, R. (2003). Teachers' gestures facilitate students' learning: A lesson in symmetry. Contemporary Educational Psychology 28, 187-204.

Wimmer, R. D., \& Dominick, J. R. (2000). Mass Media Research: An Introduction. Boston, Mass: Wadsworth, Cengage Learning. 